Bull. Mater. Sci., Vol. 17, No. 2, April 1994, pp. 111-119. (C) Printed in India.

\title{
Microstructure studies on $\mathrm{Ti}^{4+}$ - and $\mathrm{Zr}^{4+}$-substituted $\mathrm{Li}-\mathrm{Zn}$ ferrites
}

\author{
R S PATIL, S S SURYAVANSHI*, S V KAKATKAR, A M SANKPAL, \\ U R GHODAKE*, S A PATIL and S R SAWANT \\ Department of Physics, Shivaji University, Kolhapur 416004, India \\ * Department of Physics, Shivaji University, Centre for Post-Graduate Studies, Solapur \\ 413003, India \\ MS received 12 July 1993; revised 15 November 1993
}

\begin{abstract}
XRD and microstructure studies were carried out on $\mathrm{Ti}^{4+}$ and $\mathrm{Zr}^{4+}$-substituted $\mathrm{Li}-\mathrm{Zn}$ ferrites prepared by standard ceramic technique. All the ferrite compositions exhibit single phase formation. The lattice parameter $a$ increases linearly with the content of $\mathrm{Zn}^{2+} \mathrm{Zr}^{4+}$ and $\mathrm{Zn}^{2+} \mathrm{Ti}^{4+}$, which is attributed to the ionic volumes of the cations involved. With substitution by $\mathrm{Zr}^{4+}$ the average size decreases, while with substitution by $\mathrm{Ti}^{4+}$ the grain size increases. In both the series grain size varies with the composition. Excess substitution of $\mathrm{Zr}^{4+}(x>0.4)$ leads to the formation of secondary images and discontinuous grain growth. Both $\mathrm{Zr}^{4+}$ and $\mathrm{Ti}^{4+}$ compositions obey $\mathrm{Kurtz}$ theory.
\end{abstract}

Keywords. Microstructure; grain size.

\section{Introduction}

Understanding and control of microstructure in ferrites is important because many properties such as mechanical strength, electrical conductivity, magnetic susceptibility, optical transmission, etc. are strong functions of microstructure (Yan et al 1976; Postupolski 1989).

For specimens of the same composition, the dielectric permittivity of ferrites is related to the average grain size (Mioshkin et al 1981).

For polycrystalline ferrites microstructure means porosity, grain structure and phases detectable by micrographic analysis. In this communication we report the grain size and spatial features of granular structure of $\mathrm{Ti}^{\mathbf{4}^{+}}$- and $\mathrm{Zr}^{4+}$-substituted $\mathrm{Li}-\mathrm{Zn}$ ferrite.

\section{Experimental}

Ferrites of the composition $\mathrm{Li}_{0.5} \mathrm{Zn}_{x} \mathrm{Zr}_{x} \mathrm{Fe}_{2 \cdot 5-2 x} \mathrm{O}_{4}(x=0,0 \cdot 1,0 \cdot 2,0 \cdot 3,0 \cdot 4,0 \cdot 5)$ and $\mathrm{Li}_{0.5} \mathrm{Zn}_{x} \mathrm{Ti}_{x} \mathrm{Fe}_{2.5-2 x} \mathrm{O}_{4}(x=0,0.1,0.2,0.3,0.4,0.5)$ were prepared by the standard ceramic method using AR grade oxides of $\mathrm{Li}_{2} \mathrm{CO}_{3}, \mathrm{ZrO}_{2}, \mathrm{TiO}_{2}, \mathrm{ZnO}$ and $\mathrm{Fe}_{2} \mathrm{O}_{3}$. Pre-sintering of powders was carried out for $8 \mathrm{~h}$ at $725^{\circ} \mathrm{C}$, while the final sintering was done at $1100^{\circ} \mathrm{C}$. The compositions were cooled in the furnace at $80^{\circ} \mathrm{C} / \mathrm{h}$. X-ray diffraction studies were carried out with a Philips PW 1820 diffractometer using $\mathrm{Fe} \mathrm{K}_{\alpha}$ radiation.

In order to determine the average grain size, SEM micrographs of all compositions were taken using a well-polished pellet surface. The average grain size has been evaluated by using the method already described (Ishikawas et al 1989). About 10 SEM micrographs for each composition were used to compute average grain size and spatial features of granular structure. 


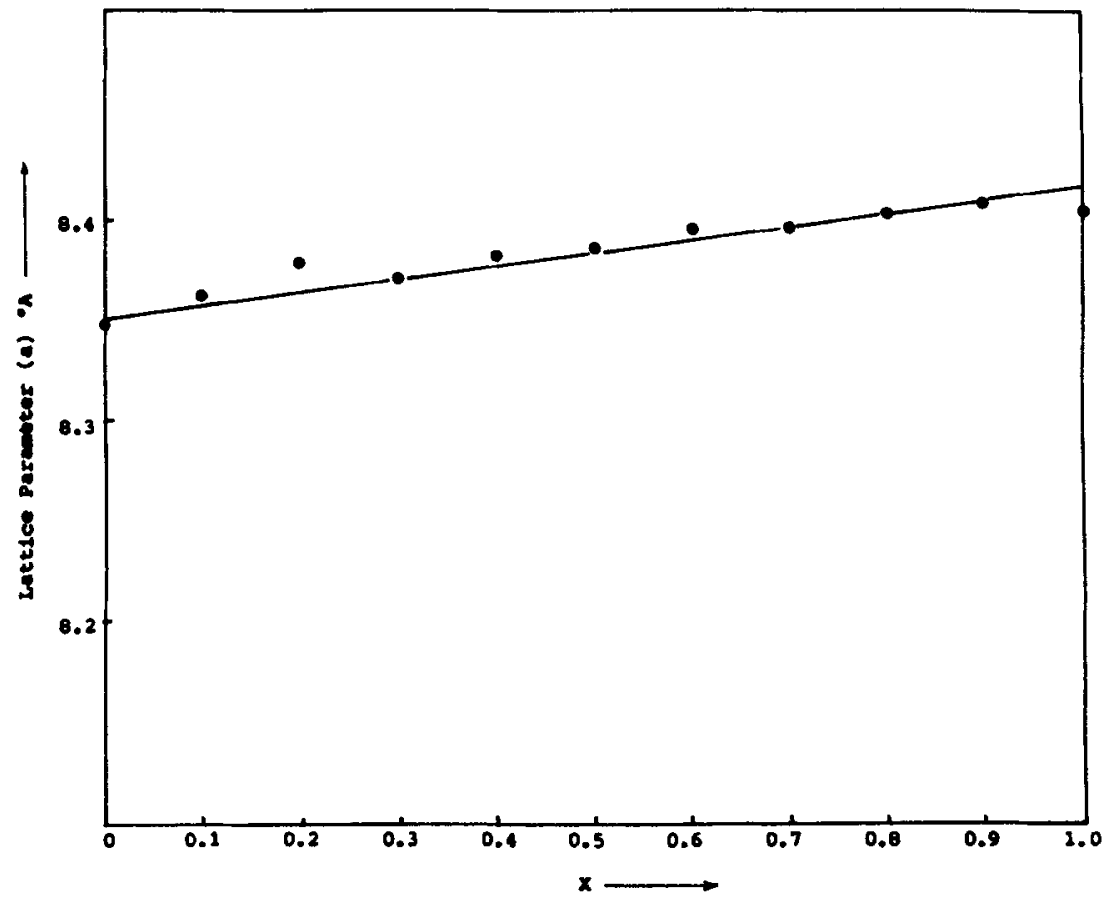

Figure 1. Compositional variation of the lattice parameter for the series $\mathrm{Li}_{\mathbf{0} \cdot \mathbf{s}} \mathrm{Zn}_{\mathbf{x}} \mathbf{T i}_{\mathbf{x}}$. $\mathrm{Fe}_{2.9-2 x} \mathrm{O}_{4}$.

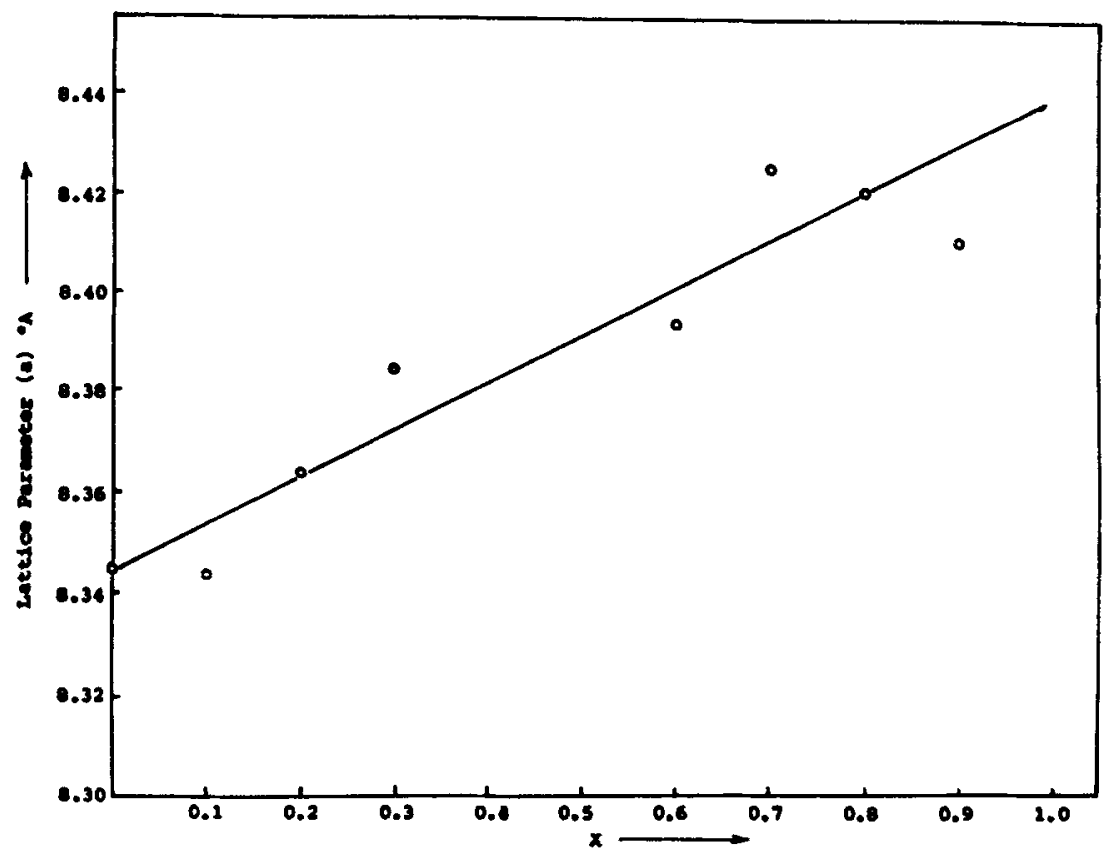

Figure 2. Compositional variation of the lattice parameter for the series $\mathrm{Li}_{0.5} \mathrm{Zn}_{\mathbf{x}} \mathbf{Z r}_{\mathbf{x}}$. $\mathrm{Fe}_{2 \cdot 5-2 x} \mathrm{O}_{4}$. 


\section{Results and discussion}

In figure 1 variation of the lattice parameter $a(\AA)$ with the content of TiZn, i.e. $x$ for the series $\mathrm{Li}_{0.5} \mathrm{Ti}_{x} \mathrm{Zn}_{x} \mathrm{Fe}_{2.5-2 x} \mathrm{O}_{4}(x=0,0 \cdot 1,0 \cdot 2, \ldots, 1)$, is given. Concentration of $\mathrm{Li}^{1+}$ ions $(0.6 \AA)$ is kept constant. An increase of $\mathrm{Zn}^{2+}(0.74 \AA)$ and $\mathrm{Ti}^{4+}(0.68 \AA)$ reduces the $\mathrm{Fe}^{3+}(0.67 \AA)$ concentration. Thus an increase of $a$ with increase of $x$ is due to ionic volumes of $\mathrm{Ti}^{4+}$ and $\mathrm{Zn}^{2+}$.

The lattice parameter $a$ in figure 2 increases with content of $\mathrm{ZrZn}$. Concentration of $\mathrm{Li}^{1+}$ ions $(0.60 \AA)$ is kept constant. An increase of $\mathrm{Zn}^{2+}(0.74 \AA)$ and $\mathrm{Zr}^{4+}(0.80 \AA)$ reduces the $\mathrm{Fe}^{3+}(0.67 \AA)$ concentration. Thus an increase of $a$ with increase of $x$ is due to ionic volumes of $\mathrm{Zr}^{4+}$ and $\mathrm{Zn}^{2+}$. The completion of the solid state reaction and single phase formation of the composition have been confirmed from $\mathrm{X}$-ray diffraction patterns as shown below (XRDs 1 and 2).

From SEM photographs shown in figures 3 and 4 the grain size $D m$ is calculated by (i) drawing a diagonal on the photograph, (ii) measuring the maximum unidirectional particle size in the vertical direction against the diagonal, and (iii) averaging the maximum unidirectional particle size.

In table 1 the data on grain size of various compositions is given.

From table 1 it is seen that for the system $\mathrm{Li}_{0.5} \mathrm{Ti}_{x} \mathrm{Zn}_{x} \mathrm{Fe}_{2.5-2 x} \mathrm{O}_{4}$, with the addition of $\mathrm{Ti}_{x} \mathrm{Zn}_{x}$ the average grain diameter $\operatorname{Dm}(\mu \mathrm{m})$ increases up to $x=0.3$ and decreases for $x>0 \cdot 3$. However, the grain size of all the substituted ferrites is greater than that of unsubstituted ferrite, i.e. Li ferrite. From the photographs (figure 3) some observations have been made: (i) the grain growth is continuous and there are no exaggerated grains, (ii) secondary electron images do not appear in any of the micrographs, and (iii) the pore size does not show any regular trend with increase of TiZn concentration. In all the cases pore size is between 0.5 and $1 \mu \mathrm{m}$.

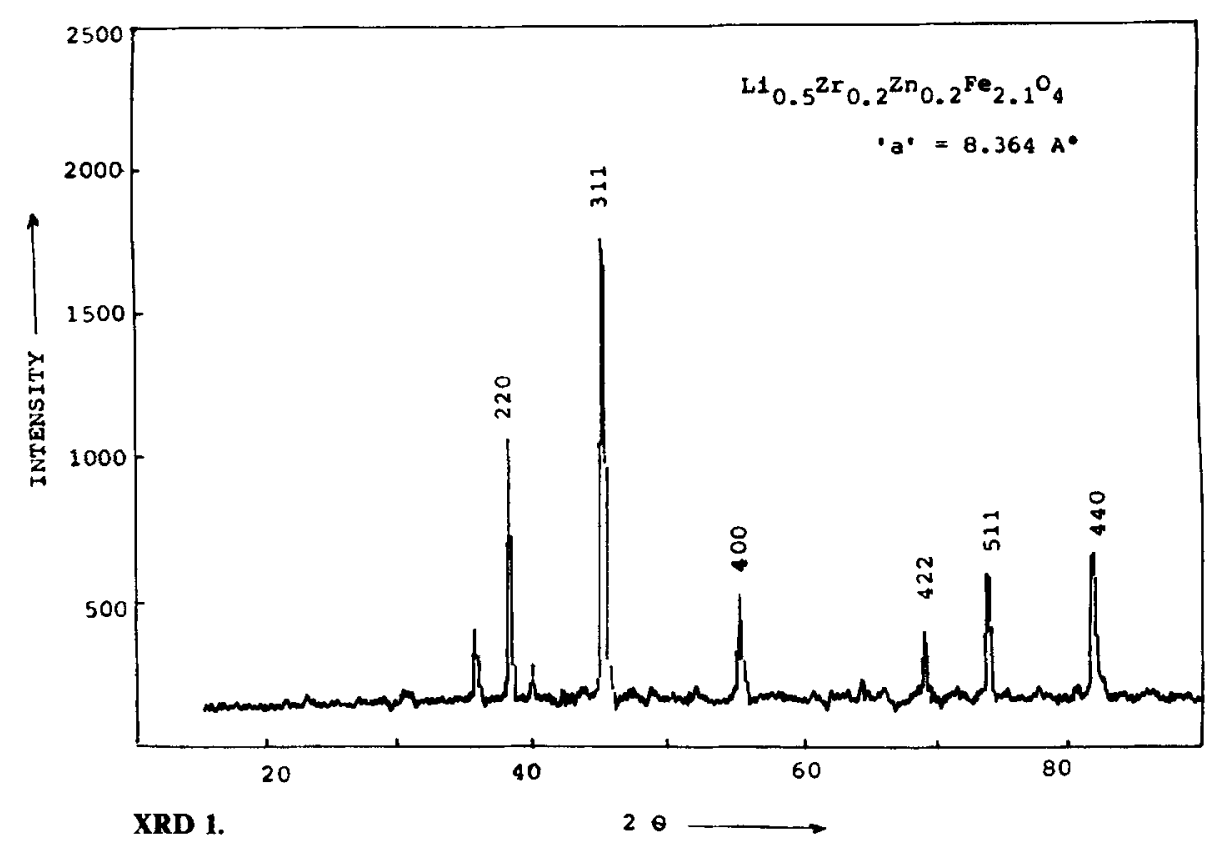



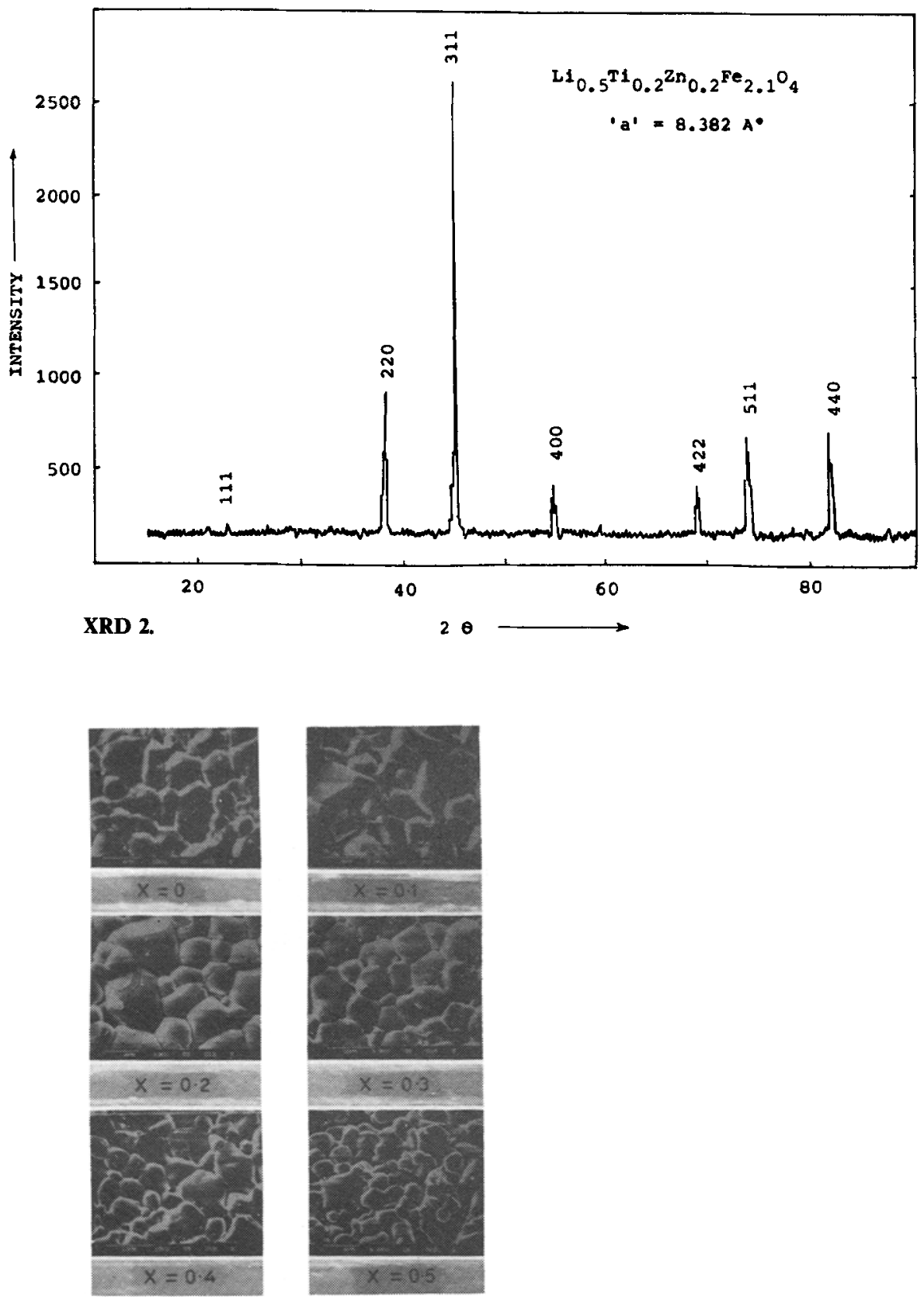

Figure 3. Microstructure photographs for the compositions $\mathrm{Li}_{0.5} \mathrm{Zn}_{x} \mathrm{Ti}_{x} \mathrm{Fe}_{2 \cdot 5-2 x} \mathrm{O}_{4}$.

In order to adequately characterize this structure, the spatial dimensions and shapes of grains of which the polycrystalline material is built should be determined first. This should be of statistical character because the grains forming the real polycrystalline material are differentiated in size and shape. The microstructural examinations of the opaque granular solids are formed mainly for two-dimensional images of the 

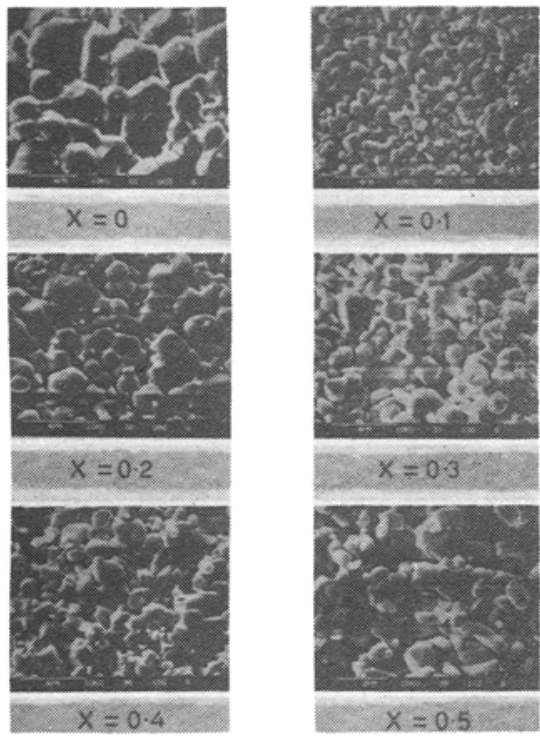

Figure 4. Microstructure photographs for the compositions $\mathrm{Li}_{0.5} \mathrm{Zn}_{x} \mathrm{Zr}_{x} \mathrm{Fe}_{2 \cdot 5-2 x} \mathrm{O}_{4}$.

Table 1. Composition and grain size.

\begin{tabular}{|c|c|c|c|}
\hline \multicolumn{2}{|c|}{$\mathrm{Li}_{0.5} \mathrm{Zr}_{x} \mathrm{Zn}_{x} \mathrm{Fe}_{2 \cdot 5-2 x} \mathrm{O}_{4}$} & \multicolumn{2}{|c|}{$\mathrm{Li}_{0.5} \mathrm{Ti}_{x} \mathrm{Zn}_{x} \mathrm{Fe}_{2 \cdot 5-2 x} \mathrm{O}_{4}$} \\
\hline $\begin{array}{l}\text { Composition } \\
x\end{array}$ & $\begin{array}{c}\text { Grain size } \\
\operatorname{Dm}(\mu \mathrm{m})\end{array}$ & $\begin{array}{c}\text { Composition } \\
x\end{array}$ & $\begin{array}{c}\text { Grain size } \\
D m(\mu \mathrm{m})\end{array}$ \\
\hline $0 \cdot 0$ & $2 \cdot 74$ & $0 \cdot 0$ & $2 \cdot 74$ \\
\hline 0.1 & 0.93 & $0 \cdot 1$ & $2 \cdot 81$ \\
\hline $0 \cdot 2$ & 1.63 & $0 \cdot 2$ & $4 \cdot 01$ \\
\hline $0 \cdot 3$ & 1.70 & $0 \cdot 3$ & 6.00 \\
\hline $0 \cdot 4$ & $1 \cdot 15$ & $0 \cdot 4$ & $4 \cdot 69$ \\
\hline 0.5 & $0 \cdot 81$ & 0.5 & $2 \cdot 86$ \\
\hline
\end{tabular}

granular structure. Such images are obtained by the random plane cross-section of a sample. For each planar image the size $D m$ and number of sides $n$ have been determined for each individual grain cross-section (having a polygon shape). Independently, the coordination number $k_{n}$ (number of nearest neighbours) for each grain crosssection have also been determined. The grain cross-section size $D m$ is the planar granulometric parameter, the number $n$ and $k_{n}$ are the planar topological parameters of the plane image of granular structure (figures 5 and 6).

The main results of the analysis are as follows: The number of neighbours $k_{n}$ of the planar grain cross-section (being a polygon) is statistical, equal to the number of its sides $n$.

The number of sides $n$ of the polygon, being a result of averaging the statistically large number of random planar intersections of one polyhedron, is linked with the number of faces $F$ of this polyhedron by the following topological relationship 

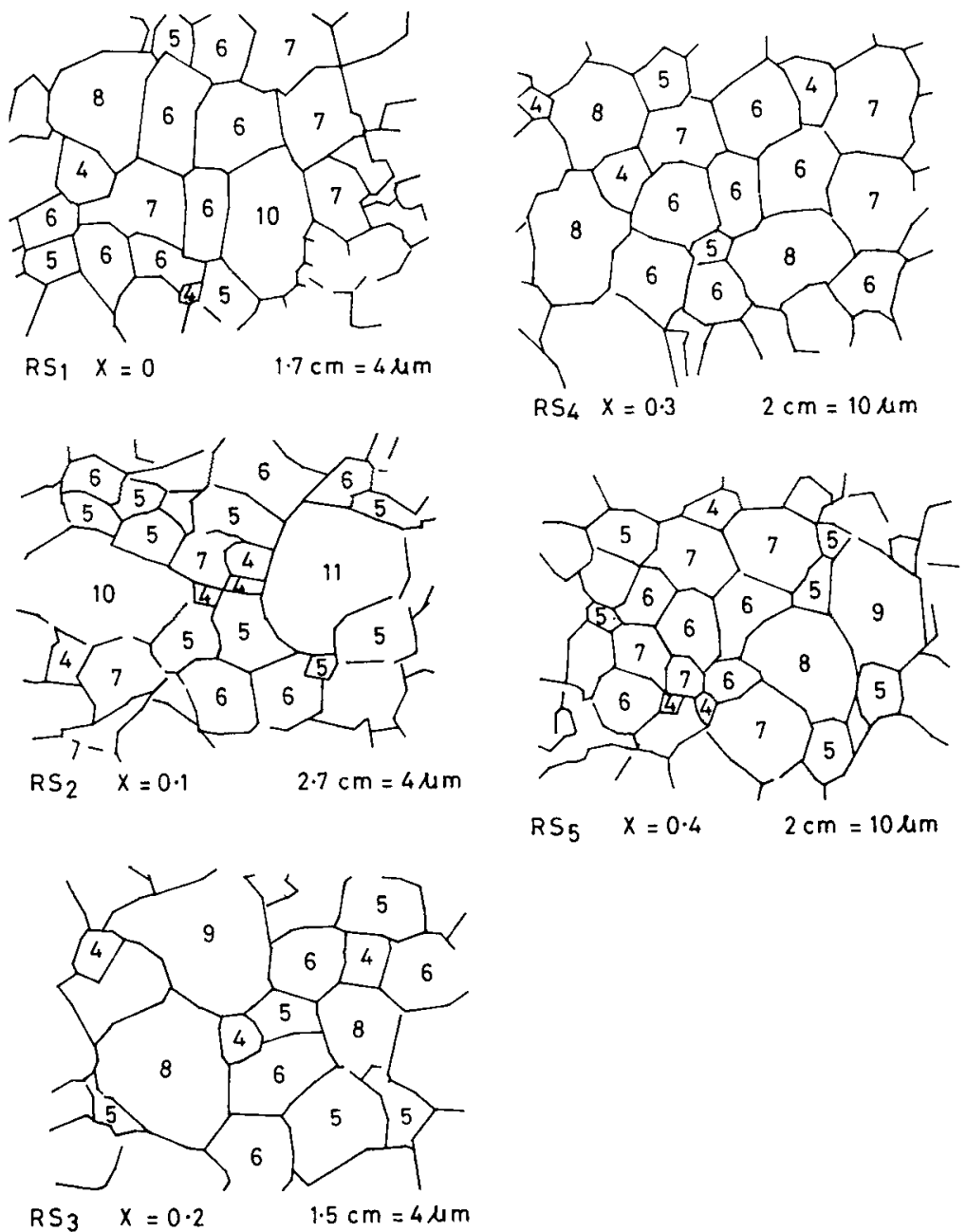

Figure 5. Fragment of the drawn contours of planar grain cross-section with marked numbers of nearest neighbour (coordination numbers) for ZnTi system.

(Postupolski et al 1988):

$$
n=(\pi / 2) \sqrt{F} .
$$

As it has been reported (Hald 1952) this formula is valid not only for regular polyhedra with regular faces but also for the irregular polyhedra with various faces.

As the relationship between $n$ and $F$ is known, the type of distribution of number of grain faces $F, G(F)$ can be obtained starting from the known distribution function of $n, g(n)$. Using a transformation formula,

$$
G(F)=g(n) \frac{\mathrm{d} n}{\mathrm{~d} F},
$$

for

$$
n=f(F)=0 \cdot 5 \pi \sqrt{F}
$$



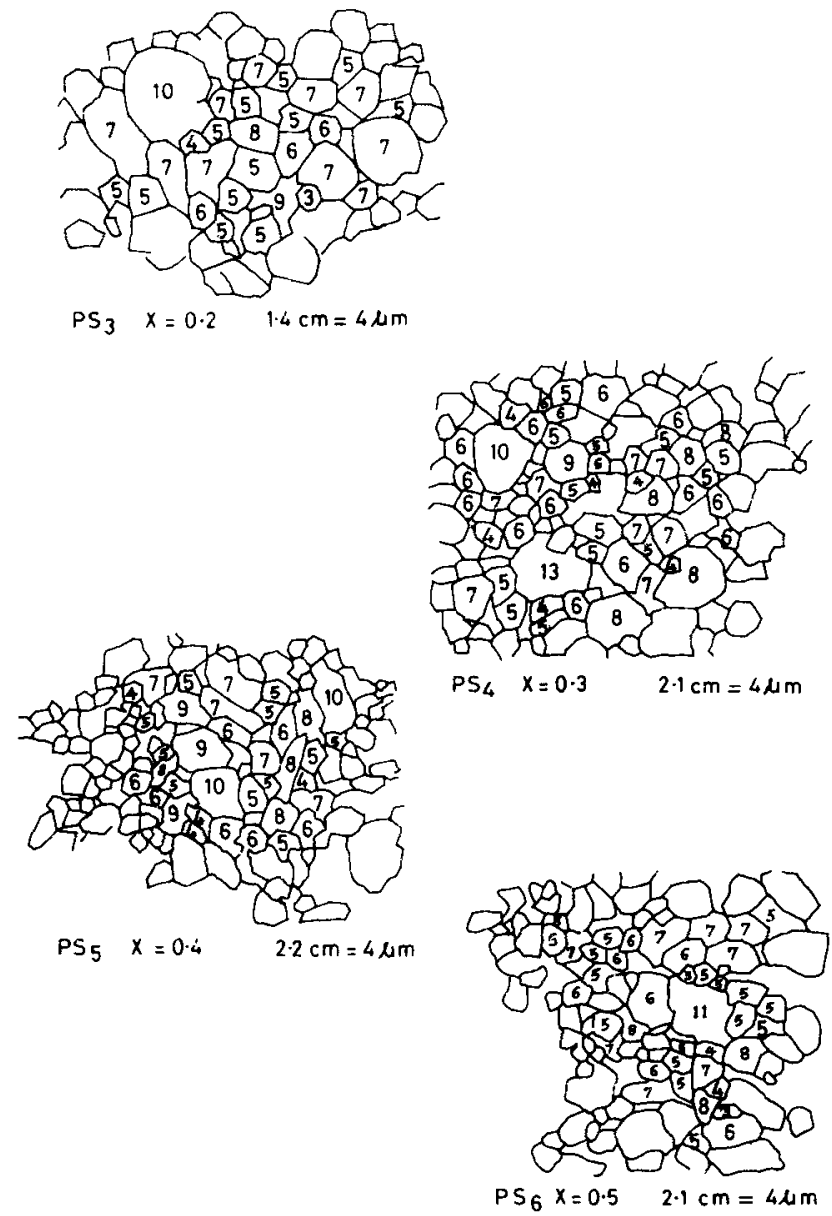

Figure 6. Fragment of the drawn contours of planar grain cross-section with marked numbers of nearest neighbours (coordination numbers) for $\mathrm{ZnZr}$ system.

It is observed that for all the compositions

$$
\begin{gathered}
n_{\mathrm{av}}=6.1 \text { and } F\left(n_{\mathrm{av}}\right)=15, \\
n_{\max }=12 \text { and } F\left(n_{\max }\right)=60 .
\end{gathered}
$$

From the data on grain size $D m$ for $\mathrm{Li}_{0.5} \mathrm{Zr}_{x} \mathrm{Zn}_{x} \mathrm{Fe}_{2.5-2 x} \mathrm{O}_{4}$ series given in table 2, the following observations have been made:

(i) With the addition of $\mathrm{ZnZr}$ in the system the grain size $\mathrm{Dm}$ decreases. Grain size of $\mathrm{Li}_{0.5} \mathrm{Fe}_{2.5} \mathrm{O}_{4}$ sample is greater than that of all the substituted samples.

(ii) The grain size $\mathrm{Dm}$ initially decreases on addition of $\mathrm{ZnZr}$, then it increases and reaches a value $1 \cdot 70 \mu \mathrm{m}$ for the sample with $x=0 \cdot 3$, and for further increase of $x$ Dm shows a decreasing trend.

(iii) From the micrographs of the samples (figure 4) it is seen that the average pore size for all the samples varies from $0.5 \mu \mathrm{m}$ to $0.88 \mu \mathrm{m}$. However there is no systematic variation of pore size and content of $\mathrm{ZnZr}$, i.e. $x$. 
(iv) For $x>0.4$ secondary images tend to appear. These images become distinct in the sample with $x=0.5$. Thus the secondary images appear to be compositionsensitive. The average size of the secondary image is $0.31 \mu \mathrm{m}$.

(v) It is also seen that grain growth tends to be discontinuous with addition of $\mathrm{ZnZr}$, promoting exaggerated grain growth.

Table 2. Data on de resistivity $\rho_{\mathrm{dc}}$ for the series $\mathrm{Li}_{0.5} \mathrm{Zn}_{\mathbf{x}} \mathrm{Zr}_{\mathbf{x}}$.

$\mathrm{Fe}_{2 \cdot 5-2 x} \mathrm{O}_{4}$.

\begin{tabular}{lc}
\hline $\begin{array}{l}\text { Composition } \\
(x)\end{array}$ & $\begin{array}{c}\mathrm{dc} \times 10^{5} \\
(\Omega \mathrm{m})\end{array}$ \\
\hline $0 \cdot 0$ & 3 \\
0.1 & 25 \\
0.2 & 33 \\
0.3 & 62 \\
0.4 & 98 \\
\hline
\end{tabular}

Table 3. Grain size and frequency.

\begin{tabular}{|c|c|c|}
\hline $\begin{array}{l}\text { Neighbours } \\
\text { (n) }\end{array}$ & $\begin{array}{c}\text { Grain size } \\
\operatorname{Dm}(\mu \mathrm{m})\end{array}$ & Frequency \\
\hline 3 & 1.65 & 1 \\
\hline \multirow[t]{3}{*}{4} & 1.45 & 4 \\
\hline & 1.86 & 3 \\
\hline & 0.72 & 8 \\
\hline \multirow[t]{5}{*}{5} & $2 \cdot 18$ & 6 \\
\hline & $6 \cdot 00$ & 3 \\
\hline & 3.00 & 3 \\
\hline & $4 \cdot 30$ & 5 \\
\hline & 0.92 & 42 \\
\hline \multirow[t]{4}{*}{6} & 1.77 & 4 \\
\hline & $3 \cdot 75$ & 9 \\
\hline & 6.00 & 10 \\
\hline & $1 \cdot 14$ & 26 \\
\hline \multirow[t]{3}{*}{7} & 3.50 & 5 \\
\hline & 7.00 & 9 \\
\hline & $1 \cdot 33$ & 27 \\
\hline \multirow[t]{4}{*}{8} & 4.00 & 1 \\
\hline & $6 \cdot 60$ & 1 \\
\hline & $8 \cdot 50$ & 3 \\
\hline & 1.71 & 11 \\
\hline \multirow[t]{2}{*}{9} & $5 \cdot 80$ & 1 \\
\hline & 1.43 & 4 \\
\hline \multirow[t]{3}{*}{10} & $3 \cdot 26$ & 1 \\
\hline & $4 \cdot 23$ & 1 \\
\hline & $2 \cdot 10$ & 4 \\
\hline \multirow[t]{2}{*}{11} & $2 \cdot 28$ & 1 \\
\hline & $3 \cdot 26$ & 1 \\
\hline 12 & - & - \\
\hline 13 & $3 \cdot 1$ & 1 \\
\hline
\end{tabular}


Discontinuous grain growth is expected to increase the intergranular porosity of the matrix resulting in increase of $\rho_{\mathrm{dc}}$ as seen from table 2.

On comparing grain sizes of $\mathrm{Li}_{0.5} \mathrm{Ti}_{x} \mathrm{Zn}_{x} \mathrm{Fe}_{2.5-2 x} \mathrm{O}_{4}$ and $\mathrm{Li}_{0.5} \mathrm{Zr}_{x} \mathrm{Zn}_{x} \mathrm{Fe}_{2.5-2 x} \mathrm{O}_{4}$ compositions, it is seen that the average grain size of all compositions of $\mathrm{Li}_{0.5} \mathrm{Zr}_{x}$. $\mathrm{Zn}_{x} \mathrm{Fe}_{2 \cdot 5-2 x} \mathrm{O}_{4}$ is smaller. The smaller grain size resulted in $\mathrm{X}$-ray line broadening in XRD.

The formula $n=0.5 \pi \sqrt{F}$ is used to fix sides of polyhedron, and the observations are similar to the previous one, i.e.

$$
\begin{gathered}
n_{\mathrm{ay}}=6.1 \text { and } F\left(n_{\mathrm{av}}\right)=15, \\
n_{\max }=12 \text { and } F\left(n_{\max }\right)=60 .
\end{gathered}
$$

These values agree closely with the corresponding values of $n_{\mathrm{av}}$ and $n_{\max }$ reported for samples of $\mathrm{Ni}-\mathrm{Zn}$ and $\mathrm{Mn}-\mathrm{Zn}$ ferrites (Postupolski 1989).

An interesting result that follows from theory developed by Kurtz and Carpay (1980) is that maximum to median grain size should be constant at a value $D_{\max } / D_{\text {med }}=e$.

In $\mathrm{TiZn}$-substituted series that ratio is about 1.5 while in $\mathrm{Zr} \mathrm{Zn}$-substituted system it is $\mathbf{1 . 6}$.

In table 3 data on number of nearest neighbours $(n)$, frequency and average grain size obtained from the SEM photographs of all compositions are given.

From table 3 it is clear that the tendency to show maximum coordination number is with $n=5,6$ and 7 .

\section{References}

Hald A 1952 Statistical theory with engineering applications (New York: J Wiley and Sons)

Ishikawas S, Mochizuki T and Sasaki I 1989 Proceedings of ICF-5 (eds) C M Srivastava and M J Patni (New Delhi: Oxford and IBH Publishing Company) p. 651

Kurtz S K and Carpay F M A 1980 J. Appl. Phys. 515725

Mioshkin V P, Panova Y I and Passynkov V V 1981 Phys. Status Solidi a66 779

Postupolski T 1988 Prace Inst. Telei Radio technicznego Zesz 107/87 1

Postupolski T 1989 Proceedings of ICF-5 (eds) C M Srivastava and M J Patni (New Delhi: Oxford and IBH Publishing Company) p. 639

Yan M F, Canon R M and Bowen H K 1976 Ceramic microstructures (eds) R F Fulrath and J Pask

(Boulder, Colorado: Westview) p. 276 